\title{
Muralismo y pedagogía otomí
}

\section{Muralism and Otomi pedagogy}

DOI: https://doi.org/10.32870/dse.v0i24.802

\section{Jorge Uzeta Iturbide*}

\begin{abstract}
Resumen
A partir de un seguimiento etnográfico, en este artículo se analizan tres murales ubicados en la escuela primaria otomí "Miguel Hidalgo" de la comunidad de Cieneguilla, en Tierra Blanca, Guanajuato. Siendo expresiones artísticas y pedagógicas generadas circunstancialmente, se argumenta que estos murales se encuentran asociados con un "curriculum cultural" que suma prácticas sociales, creencias y mitología otomí con otros referentes de carácter nacional. Por lo mismo, y pese a sus diferencias formales y temáticas, los murales escolares aluden a una narrativa de actualización étnica, actualmente coincidente con las políticas multiculturales del Estado mexicano.
\end{abstract}

Palabras clave: muralismo - pedagogía - curriculum cultural - multiculturalismo.

\begin{abstract}
Based on ethnographic work, this article analyzes three mural paintings located in the "Miguel Hidalgo" Otomi primary school of the Cieneguilla community in the municipality of Tierra Blanca, Guanajuato, Mexico. Being artistic and pedagogical expressions generated circumstantially, we argue that these murals are associated with a "cultural curriculum" that adds social practices, beliefs and Otomi mythology to other national references. For the same reason, and despite their formal and thematic differences, school murals allude to an ethnic update narrative which coincides with the current multicultural policies of the Mexican state.
\end{abstract}

Key words: muralism - pedagogy - cultural curriculum - multiculturalism.

\section{Una escuela otomí}

Bajo la impronta revolucionaria, que proponía la transformación cultural y socioeconómica del medio rural, la escuela pública mexicana y los programas de educación indígena que le sucedieron se constituyeron en herramientas fundamentales de la pedagogía promovida por el Estado

1 Agradezco al CIESAS-Peninsular, en Mérida, Yucatán, el apoyo que me otorgó para el trabajo de campo y la redacción de este artículo durante una estancia sabática. Extiendo mi gratitud a mi institución de adscripción, El Colegio de Michoacán.

* Doctor en Ciencias Sociales. Líneas de investigación: etnicidad, cultura, leyes indígenas. Centro de Estudios Antropológicos de El Colegio de Michoacán. México.jorgeuzeta@colmich.edu.mx 
(Hewitt, 1988: 30-34). Abocadas inicialmente a la "mexicanización" de poblaciones rurales tal como lo proponía el proyecto indigenista, aquellos programas contribuyeron a introducir en muchas comunidades indígenas cánones occidentales de higiene, deporte y ciencia, impulsando la infraestructura correspondiente. ${ }^{2}$

Si uno deambula al azar por localidades específicas teniendo en mente lo anterior, pronto se encontrará con indicios materiales de aquellos esfuerzos de equipamiento: redes hidráulicas, caminos vecinales, canchas deportivas $\mathrm{y}$, entre otras cosas, algunos servicios de salubridad. $\mathrm{Si}$ se camina por Cieneguilla, localidad central de las 19 comunidades otomíes que conforman la Congregación de San Ildefonso de Cieneguilla, en el municipio guanajuatense de Tierra Blanca, sin duda deberá sumar el edificio de la escuela primaria como parte nodal de los desempeños señalados.

Apenas a un par de cuadras del templo dedicado al santo patrón - con su piso atrial cuajado de imágenes rituales - y remontando loma arriba en dirección a la comunidad de Cañada de Juanica, la escuela primaria bilingüe Miguel Hidalgo llama de inmediato la atención por su extensión y lo bien cuidado de sus instalaciones. También porque la entrada principal se encuentra sobre la "calle Padre Albino", bautizada así en honor del sacerdote que impulsó y gestionó la fundación de esa primaria pública hace más de medio siglo.

Al acceder a las instalaciones escolares se puede confirmar su pulcritud y buena organización: a la entrada, en línea con diferentes juegos infantiles ubicados entre una cuidada vegetación, pero en un espacio particular y acotado, se levanta un busto de cantera en homenaje permanente a aquel sacerdote (véase imagen 1). Un poco más adelante, una figura rectangular ofrece en una de sus caras la imagen de una bandera nacional, mientras en otra se da la bienvenida al visitante, en español y en hñahñu (véase imagen 2$)_{;}^{3}$ a mano derecha se sitúan la dirección escolar y algunos espacios para servicios, dejando lugar para varias aulas, la más cercana de las cuales presenta en su parte posterior un mural que incluye un extenso poema. La mirada pronto es atraída hacia la mitad del patio, en donde se alza una estatua de Miguel Hidalgo, con el prócer enfebrecido llamando a la insurrección (véase imagen 3).

2 Como política del Estado posrevolucionario, el proyecto indigenista buscó sucesivamente integrar e incorporar a la población indígena al desarrollo nacional. La extensa obra de Gonzalo Aguirre Beltrán (1988) da buena cuenta de sus fundamentos teóricos. Sobre sus muchos programas, cabe mencionar tres ejemplos que involucraron a diferentes instituciones: en 1911, la "Escuela de Instrucción Rudimentaria" estuvo perfilada a "Enseñar a los indígenas a hablar, leer y escribir en castellano y operaciones aritméticas fundamentales"; en 1917, la “Dirección de Antropología y Poblaciones Regionales" promovió acciones de "Educación integral nacionalista”; en 1925, los "Misioneros culturales" trabajaron para "castellanizar y civilizar". Este tipo de programas se mantuvieron con diferentes objetivos y, a través de diferentes instituciones, hasta bien entrada la década de 1960 (México Indígena, 1978: 385-386).

3 La planeación y ejecución de las imágenes de ese rectángulo, bastante sencillas, no son comparables al diseño y ejecución de los murales, aunque sean importantes en la narrativa visual de la escuela. La bandera es una copia de las estampas que pueden conseguirse en cualquier papelería, mientras que la bienvenida es un rótulo que carece de relevancia plástica. 


\section{Imagen 1}

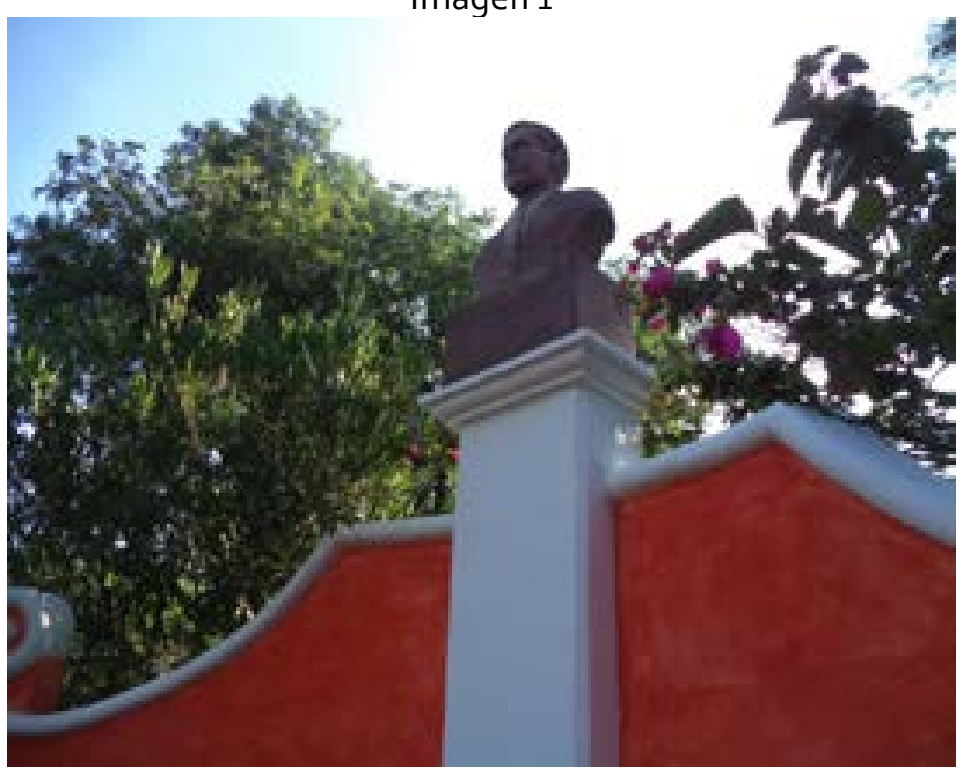

Busto del padre Alvino González, a la entrada de la escuela primaria Miguel Hidalgo, Cieneguilla, Tierra Blanca, Guanajuato. Todas las fotografías fueron tomadas por el autor entre 2019 y 2020.

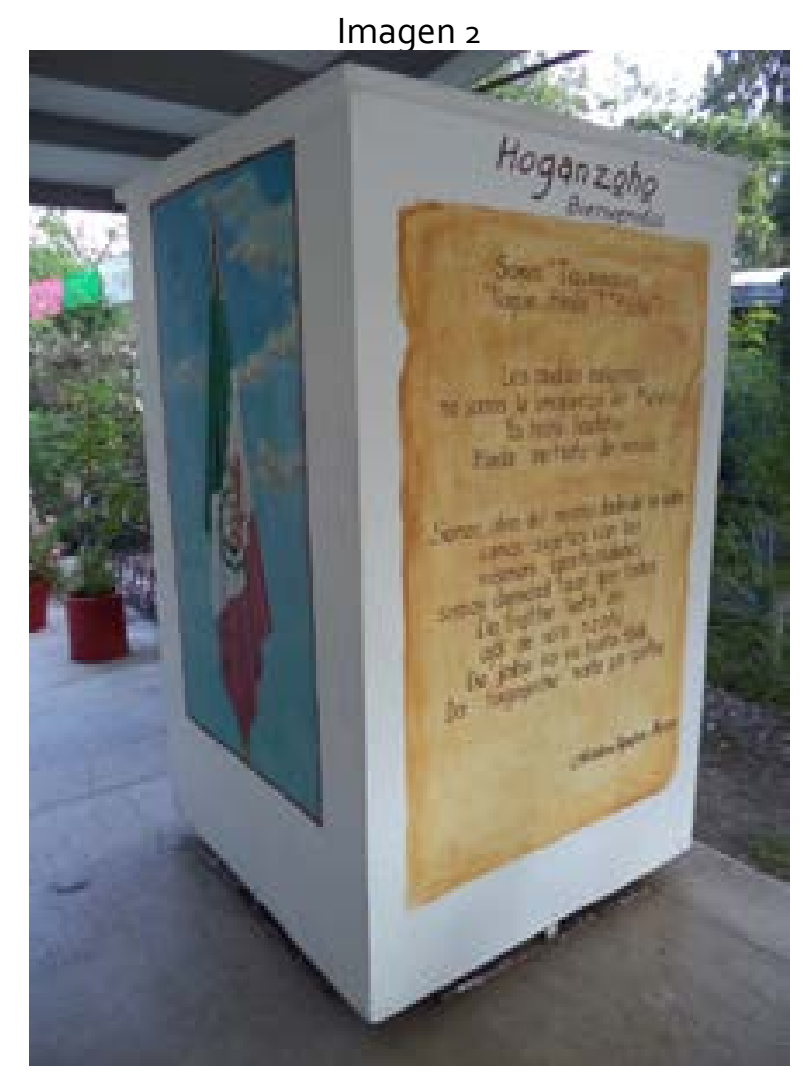


Bienvenida a la entrada de la escuela primaria Miguel Hidalgo, Cieneguilla, Tierra Blanca, Guanajuato. Imagen 3

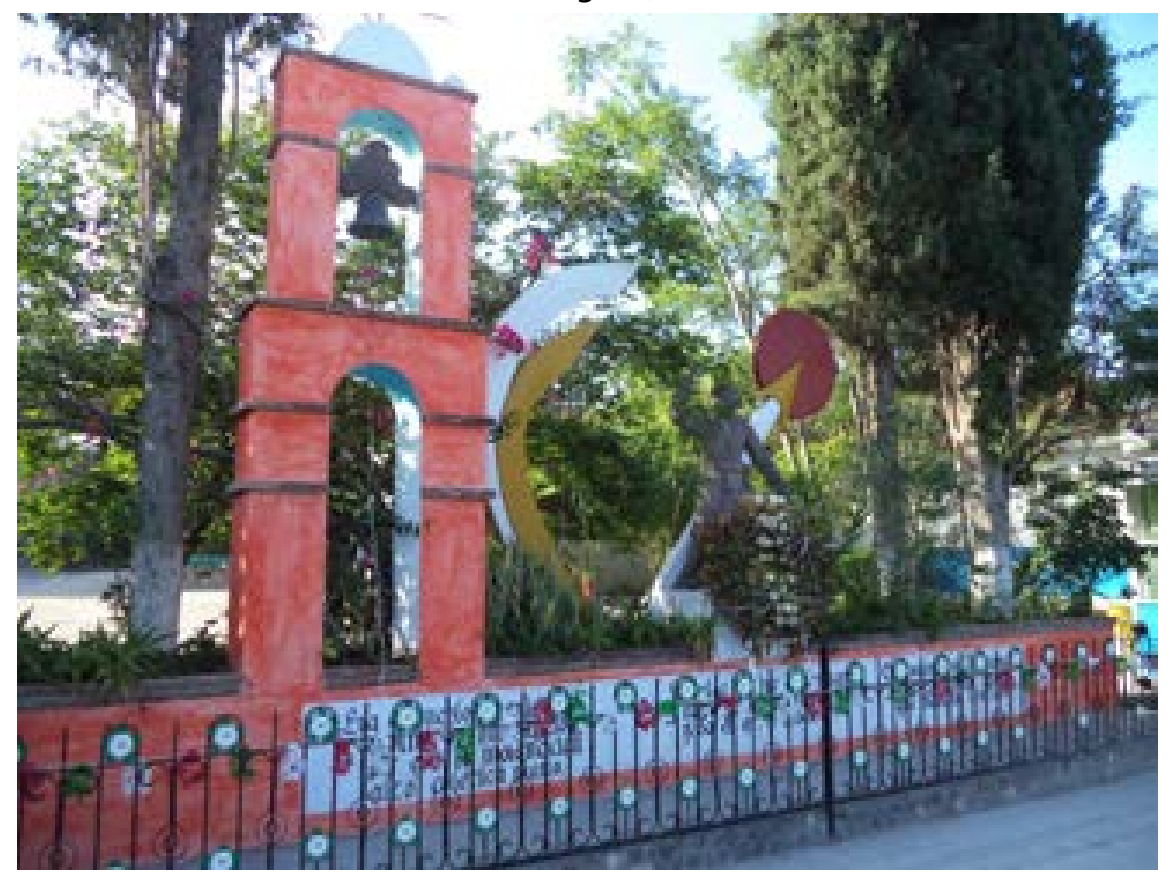

Estatua de Miguel Hidalgo, patio de la escuela Miguel Hidalgo, Cieneguilla, Tierra Blanca, Guanajuato.

Más allá de ese primer bloque, pasando un terregoso campo de futbol limitado en uno de sus extremos por otra llamativa pintura mural, se ubican las aulas restantes; al final de la escuela y hacia su esquina derecha, cerca del conjunto formado por una cocina, un comedor y un "Jardín de los abuelitos" dedicado a la memoria de los antepasados, se destaca un "salón de usos múltiples", techado y acondicionado con pequeñas gradas para hacerlo funcionar también como cancha deportiva. Su pared limítrofe ofrece la tercera pintura mural del plantel, la de más reciente ejecución.

No resulta extraño que al finalizar el recorrido el director de la primaria le acerque a uno el "Libro de visitantes" pidiendo dejar ahí un comentario sobre la escuela, para continuar así una práctica instaurada por el finado profesor Aristeo Ramírez Moreno, exdirector de la misma y personaje político importante en la congregación. Los comentarios asentados en el libro suelen ser, con justicia, elogiosos.

Pese al logro político que supuso su fundación y afianzamiento, y pese a la buena imagen que el plantel ha alimentado desde su inicio, hace mucho tiempo que la escuela Miguel Hidalgo dejó de ser la única opción para todas las comunidades congregadas, pues más o menos rápidamente - y más o menos de manera conflictiva - algunos profesores se distanciaron de ella para fundar otras primarias en las comunidades restantes, por lo demás necesarias. Tampoco es la única que emplea a profesores otomíes surgidos de las mismas localidades. Sin embargo, esta 
escuela resulta emblemática del proceso vivido por la congregación en los últimos 70 años ya que fue la primera situada en las comunidades otomíes, lo que contribuyó a que estas últimas se reposicionaran en un entramado de relaciones sociales y políticas más amplias. No sólo eso, también es la que ha recibido las mayores atenciones institucionales y dotación de equipo, pues varios gobernadores y al menos un Presidente de la República la han visitado durante sus mandatos. Finalmente, es la que ha sido mejor cuidada de todas las que existen en la congregación. Por eso y por otras cosas, su actual director la califica con orgullo como una escuela "atípica".

Haciendo a un lado las densas redes de relaciones en donde esta escuela y sus docentes se han desempeñado, y que pueden abordarse simultáneamente como consustanciales a la vida política local y a la aplicación de los programas educativos impulsados por el Estado y el gobierno de la entidad, la escuela resulta representativa en otro sentido: el de su espacialidad física. Con lo anterior refiero menos a su diseño, cuyo modelo predeterminado por el Comité Administrador del Programa Federal de Construcción de Escuelas (CAPFCE) la hizo destacar en un medio rural marcado inicialmente por el uso de materiales autóctonos, y más al uso de sus instalaciones como soporte de símbolos locales. Esto es, con elementos cuyo significado subrayan las características y los posicionamientos tenidos como propios, y que de hecho han funcionado como resortes de la vida política del lugar. Esos contenidos simbólicos se destacan notablemente a través de varias de las expresiones plásticas aludidas brevemente en los párrafos anteriores.

Así pues, si la escuela es por derecho propio un destacado referente de las luchas locales y de la interlocución con distintas formaciones del Estado mexicano, su calidad simbólica radica en la capacidad para aglutinar representaciones formalmente disímbolas como parte de su concreción arquitectónica, articuladas en una narrativa política plasmada de manera fundamental, aunque no únicamente, en pinturas murales. Como expresiones artísticas son parte instrumental, o técnica, de un método de enseñanza que trasciende lo escolar, pues varias de esas representaciones plásticas se encuentran asociadas con elementos sobre los que se erige la identidad cultural otomí; en concreto, con prácticas y creencias que refieren, por una parte a una vertiente de organización social, mientras por la otra se relacionan con la recreación de referentes mitológicos. Otras representaciones también incluidas en la muralística escolar, se encuentran asociadas con la historia nacional en su versión oficial: aquella que reduce la construcción del país a los desempeños de los grandes hombres, idealizándolos con fines nacionalistas (Crespo, 2010: 11-12), versión que ha sido un elemento recurrente para caracterizar diferentes espacios institucionales por todo el país, tanto durante la posrevolución como a lo largo del periodo neoliberal.

Todas esas imágenes han sido producto de un proceso de selección que, parafraseando a Bourdieu (1991), atienden a un "plan no planeado", desarrollado al arbitrio de las circunstancias. Sin embargo, las de carácter nacional han sido acompañadas de elementos locales y de una gestualidad que hace más evidente la intención política que subyace a toda la plástica ubicada 
en la escuela. Así, lo que interesa mostrar es que, en el contexto de la congregación otomí señalada, los contenidos de las expresiones artísticas aludidas no son excluyentes aunque formalmente lo parezcan. Las imágenes que las constituyen han sido elegidas y unidas, o acopladas, de tal manera que sus significados pueden leerse como parte de un posicionamiento que interpela a las instituciones, pero que lejos de ser expresiones de "autonomía", "independencia" o "resistencia" de las comunidades otomíes (Peña, 2019; Urbina, 2016), actualmente se encuentran en sintonía con las iniciativas multiculturales de la formación neoliberal del Estado mexicano. Es decir, son expresiones de afinidad con la política estatal en curso, que reconoce constitucionalmente las diferencias culturales de la población y las defiende y estimula —al menos retóricamente - como parte de la diversidad que ha configurado al país.

Aquellas imágenes contribuyen entonces a actualizar el sentido de la identidad diferencial, sugiriendo los contrapesos, las adecuaciones y los vínculos logrados entre las comunidades otomíes, las instituciones estatales y diversos actores regionales. En este sentido, el objetivo es abordar las expresiones plásticas escolares como parte de proyecciones o iniciativas que derivan de "procesos educativos no escolarizados", lo que Pastrana (2014: 115) define como un "curriculum cultural", mismas que inciden en la interacción de las comunidades con el multiculturalismo estatal. Así, no se pretende una lectura basada en alguna teoría de análisis iconográfico, sino el rastreo de información iconográfica básica y la contextualización sociopolítica de su entorno. ${ }^{4}$ Siguiendo esta lógica, en el siguiente apartado se observará el surgimiento y desarrollo de la escuela primaria, aludiendo a algunas prácticas cotidianas marcadas por la ritualidad religiosa y asociadas con el curriculum cultural. Enseguida se atenderán las particularidades de los murales, en los sentidos con los que sus creadores han tratado de impregnarlos y en la narrativa subyacente. Finalmente, en un último apartado se buscará recapitular, adelantando una serie de señalamientos sobre el papel pedagógico de este tipo de plástica en la recreación de la identidad diferencial, término que requiere de una breve precisión.

Al recurrir a él, desde luego no se alude al concepto de identidad diferencial utilizado en el campo de la mercadotecnia. Se refiere, siguiendo a Charles Taylor, a la construcción de los individuos y de los grupos que los incluyen a partir de un contexto narrativo, social e históricamente configurado. Ahí, cultura y lengua, como elementos diacríticos de autoadscripción, e incluso de orientación del pensamiento resultan centrales. El análisis que Zárate (2015) ha realizado de los planteamientos de Taylor permite adjetivar el término de identidad, que para el propósito de este texto calza bien con los esfuerzos otomíes por actualizar el contraste y su diferencia con las poblaciones vecinas a través de expresiones culturales.

4 Se podrían trazar algunas asociaciones iniciales entre la lectura ofrecida y la teoría de Erwin Panofsky sobre las relaciones semánticas de las "formas visuales", mediante sus motivos, su expresividad y, en otro nivel, sus significados convencionales (véase una síntesis en Buxó, 2002: 35-38). No obstante, ahondar seriamente en la utilidad de esta perspectiva para el análisis del muralismo escolar es una tarea a futuro. 


\section{La educación primaria en Tierra Blanca, Guanajuato ${ }^{5}$}

La escuela primaria estatal y bilingüe Miguel Hidalgo tiene una historia poco convencional, ajena a las avanzadas de maestros "socialistas" enviados a entidades y regiones por los gobiernos de la revolución en las primeras décadas del siglo XX. De hecho, fue hasta inicios de los años cincuenta cuando la escuela se constituyó en una demanda compartida por las comunidades otomíes, sobre todo porque suponía sacudirse parte del dominio municipal que ejercían los vecinos de la cabecera, ubicada a una distancia de cinco kilómetros de Cieneguilla. Además de contar con la única primaria del entorno, a cargo del párroco del lugar, la gente de la cabecera controlaba el ayuntamiento y los pocos canales políticos locales asociados con el Comité Municipal del Partido Revolucionario Institucional (PRI). Considerándose a sí mismos como sujetos nacionales, culturalmente mestizos, este vecindario ejerció diferentes formas de dominio en perjuicio de la población otomí, concentrando para su beneficio la poca obra pública que llegaba al municipio, denostándolos como incivilizados y "no blancos" ("tashíngues"), obstaculizando su presencia en las oficinas municipales y obligándoles a cumplir con faenas de acondicionamiento urbano sin pago de por medio (Uzeta, 2004; Urbina, 2016).

Siguiendo diversos testimonios locales, tanto la primaria de la cabecera como la que poco después se lograría en la congregación, fueron posibles gracias al activismo del cura párroco Alvino González y a sus relaciones con el entonces gobernador de la entidad, José Aguilar y Maya (1949-1955). Este último, quien en su juventud había estudiado en el seminario, no objetó la propuesta del párroco para recurrir a docentes religiosas, resistiendo la oposición de los vecinos de Tierra Blanca, que exigían la concentración de servicios educativos en la cabecera, el sacerdote acudió a su diócesis en busca de maestros o maestras interesadas, y encontró el apoyo de la Congregación Mariana cuyas religiosas, asentadas posteriormente en la congregación, han fungido desde entonces como parte de la planta docente.

Rivera y van Dijk (2017: 5), que hacen eco de lo anterior, señalan además que inicialmente la escuela otomí contó con sólo cuatro grados escolares asentados a un costado del templo de Cieneguilla, pues se carecía de edificio. Para concluir la primaria, los alumnos debían ir a la escuela de la cabecera para cursar los dos años restantes, un quehacer desagradable dado el racismo de sus compañeros terrablanquenses. De acuerdo con estas autoras, los seis grados de primaria se consiguieron una vez que las aulas fueron levantadas.

De tal manera, la obtención del programa educativo en Cieneguilla fue el punto de partida para la eventual construcción del edificio escolar, posible también gracias a un notable cambio

5 A manera de nota metodológica, hay que decir que este texto es resultado de una investigación antropológica de largo aliento, enfocada en la vida cultural y política del pueblo otomí en el estado de Guanajuato. El trabajo está basado principalmente en el método etnográfico, con un trabajo de campo extenso realizado en la última década del siglo pasado y en la primera del presente, mismo que desde entonces ha sido actualizado con visitas puntuales a campo para desahogar temas y asuntos específicos. Se ha recurrido por igual, aunque de manera jerarquizada, a entrevistas semiestructuradas, a recorridos sobre terreno, a registros visuales, y al análisis y clasificación de información secundaria (hemerográfica, bibliográfica, institucional y de redes sociales). 
político: las comunidades otomíes, entonces con consensos claros y bien organizadas, lograron por primera vez que su "representante general", don Pancho Ramírez Moreno, ganara en 1967 la candidatura priísta a la presidencia municipal en una disputada convención partidista, llevándolo después a triunfar en un proceso electoral que remarcó las diferencias entre los otomíes y los vecinos de la cabecera (Uzeta, 2004). Con la presidencia en las manos, les fue posible tramitar la construcción del edificio, asegurando con esto la naturaleza irreversible del proyecto escolar pese al juego de oposiciones locales y, de paso, afirmando a la congregación en su conjunto como una entidad políticamente viable.

La ubicación de la escuela se acordó a partir de la cesión que un vecino hizo de algunos terrenos propios a cambio de asegurarse un empleo como conserje. Entonces la obra concentró los esfuerzos conjuntos de las comunidades otomíes durante los años de la década de 1960 y los iniciales de la siguiente, y eventualmente el edificio ha ido equipándose y creciendo gracias a la capacidad de gestión de la propia planta docente. En este sentido, el edificio escolar es la objetivación de una fuerte transformación política que trascendió el ámbito local, pues terminó de reubicar a la congregación y a sus dirigentes en un espacio de relaciones que involucraron a las instituciones educativas de la entidad, en su momento, a CAPFCE y al propio gobernador guanajuatense, generando y sosteniendo la aspiración a la escolaridad y a la profesionalización como objetivos principales de la juventud otomí. Muchos de los posteriores profesores adscritos laboralmente a la escuela Miguel Hidalgo y a las distintas primarias de la congregación hicieron sus estudios básicos en ese plantel.

La escuela fue un espacio notable por el efecto que tuvo en dos asuntos distintos aunque vinculados. Primero, por su impacto en la conversión de las autoridades tradicionales otomíes y, segundo, en la defensa y promoción de la cultura local. Respecto de lo primero, los propios maestros fueron concentrando mucha de la autoridad moral y política que hasta los años setenta correspondía básicamente al "representante general" de la congregación. Este último era el vértice de un sistema político originado por un peculiar proceso agrario que se remonta a 1852, que incluyó la compra de tierras a la cercana hacienda de El Capulín (Urbina, 2016; Uzeta, 2010). Apoyado por los líderes de cada comunidad, el representante general fue transformándose eventualmente en el interlocutor o delegado otomí de la presidencia municipal de Tierra Blanca. La familia Ramírez Moreno tenía un papel destacado en esta jerarquía; uno de sus miembros, el profesor Aristeo Ramírez Moreno, despuntó como director de la primaria atrayendo para sí el liderazgo político de la congregación, lo que le llevó a ser presidente municipal de Tierra Blanca a inicios de la década de $1980 .^{6}$

6 El proceso por el que se generó el liderazgo del profesor Aristeo fue complejo, y desde luego no careció de oposiciones internas. Autoras como Urbina (2016) lo identifican como un cacique; para no desviar los objetivos de este artículo, no se abundará en esa interesante discusión, sólo se adelanta que por las connotaciones éticas desfavorables que le son inherentes, el término parece excesivo y en todo caso inexacto. 
En esa posición, el profesor y su grupo de docentes se constituyeron de hecho en promotores culturales, haciendo funcionar a la escuela como un espacio para la recuperación de la cultura otomí iniciaron con la lengua, básicamente perdida a lo largo del siglo XX, y siguieron en firme con la actualización de prácticas religiosas de corte católico nativista. Es decir, a contracorriente del mandato de laicidad constitucional marcado para la educación pública, desde entonces en la escuela Miguel Hidalgo se induce a los niños a participar en la ritualidad colectiva encabezada por las mayordomías otomíes, enlazando los quehaceres del aula con formas de endoculturación y socialización impulsadas tempranamente desde la familia. En este punto se destaca un principio pedagógico, de fuerte carga política, que con frecuencia utilizaba el profesor Aristeo: "la escuela es de la congregación, no la congregación de la escuela".7 De manera que la labor docente hermanaba la enseñanza de ciencias, higiene corporal y virtudes cívicas con la educación no escolarizada, esto es, con las prácticas y creencias que de acuerdo con los profesores daban su particularidad a las comunidades.

Así, como escolares y como miembros de las comunidades, los alumnos fueron incorporados en diversos momentos a los desempeños realizados por las mayordomías en Cieneguilla, replicando en la medida de lo posible su compleja estructura (Rivera, van Dijk, 2017). Puede sugerirse entonces que en la primaria Miguel Hidalgo la enseñanza escolar se encuentra vinculada al compromiso con "la comunidad" como ente imaginado o abstracto (Civera, 2012), pero sobre todo con lo que se supone son los fundamentos sociales y simbólicos que constituyen a la congregación, mismos que tienden a ser presentados localmente como esencias: las mayordomías y el ciclo ritual. Este último involucra a todas las comunidades congregadas, y aglutina densos referentes territoriales, agrícolas e históricos (Urbina, 2016).

A propósito, Leonor Pastrana ha identificado la integración de un "currículum cultural" en "procesos educativos no escolarizados" que se encuentran presentes en las prácticas de culto. Las dimensiones que ella reconoce y que son distinguibles en la pedagogía que ha sido aludida, pero también en las tres obras plásticas pintadas en los muros escolares que serán referidos más adelante, enlazan cuestiones identitarias con valores normativos y con capacidades cognitivas. Vale la pena citar ampliamente las dimensiones que de acuerdo con esta autora constituyen aquella currícula:

1) Identitaria situacional, expresada en una visión del mundo socialmente compartida y estructurante del yo-nosotros y ellos; 2) Valoral-normativa, concretada en valores, creencias, pautas de comportamiento y criterios de juicio ético-moral e integradora de algunas disposiciones y actitudes de los sujetos ante la vida, y 3) Cognoscitiva, condensada en saberes, competencias y habilidades de diversa índole -intelectuales, emocionales, corporales, espaciales, etcétera- implicadas en las distintas prácticas del currículum cultural (Pastrana, 2014: 115).

7 Esa frase fue repetida textualmente en diversas entrevistas realizadas al profesor Aristeo Ramírez Moreno en las comunidades de Cieneguilla y Cañada de Juanica, durante la segunda mitad de la década de 1990. 
A esas dimensiones se deber sumar, de manera destacada, la fuerte impronta política implicada en el impulso pedagógico, mismo que cuadra muy bien con la reivindicación de "valores locales" en la adaptación de diferentes "estructuras nacionales", particularmente las escolares (Sigüenza, Fabián, 2013: 112). Esa huella tiene que ver también con la manera en que se define la nomenclatura de las calles y de los espacios públicos, recurriendo a prohombres locales como el párroco Alvino, pero para el caso que interesa se relaciona más claramente con las expresiones plásticas incluidas en el edificio escolar.

\section{Los murales}

De acuerdo con el profesor Celestino García Cruz, actual director de la primaria, los murales escolares "fortalecen la educación del alumno y el maestro. A los alumnos las cosas se les quedan más grabadas que con las palabras. Además, la pintura ayuda a los niños a expresarse emocionalmente". Son parte, agrega, de una "pedagogía crítica" que incluye el desempeño de los padres de familia auxiliando a sus hijos en investigaciones determinadas para que estos últimos aprendan a analizar información y a redactar sus hallazgos. En esta idea, la "proyección cultural tiene impacto en la educación del niño".

Ese es el papel de la abundante iconografía escolar, cuyas imágenes, al estar agrupadas en el propio edificio, se interpelan como parte de un discurso en el que se defienden las particularidades culturales otomíes. Es aquí donde gravitan las dimensiones de la currícula cultural, incluida la referida a la política. Veamos un ejemplo.

La escultura de Hidalgo, situada al lado de una pequeña construcción que recuerda a la iglesia de Dolores, y que hasta hace poco estuvo decorada con simbología otomí (el sol y la luna situados con la misma orientación que hombres y mujeres durante los rituales religiosos), nos presenta al héroe en el momento de la ruptura y la guerra revolucionaria. Una leyenda escrita en la base del monumento, que alude al pueblo de México y a su liberación dirigida por la mano colérica del libertador, refuerza la gestualidad del prócer.

Como mero recurso, ese "gesto emocional" estaría abierto a diferentes interpretaciones (Ginzburg, 2014: 136), no obstante, la mueca es reiterada en el último de los murales y por lo tanto no resulta gratuita en términos de su sentido: no se alude al cura Hidalgo como el fundador de un país culturalmente mestizo, recurso muy presente entre la clase política guanajuatense, sino a quien quebranta una forma de dominación colonial manteniendo la especificidad de los grupos que constituyen México. Aludiendo a la curricula cultural, la escultura forma parte de una dimensión identitaria que se refuerza — salvando la enorme distancia_ con la apacible talla

8 Entrevista al profesor Celestino García Cruz, comunidad de Cieneguilla, Tierra Blanca, Guanajuato, 11 de marzo de 2020. Estas palabras, sobre todo las referidas a la pedagogía crítica, hacen eco con los murales existentes en muchas normales rurales del país. No obstante, y a diferencia de los murales de la escuela Miguel Hidalgo, en aquellas imágenes las nociones de resistencia y lucha popular son centrales (véase CONAEN, 2020). 
realizada posteriormente en honor del párroco Alvino, quien mediante la gestión para fundar la escuela contribuyó al relajamiento de formas de dominio y de racismo, impulsando la actualización de prácticas culturales otomíes a contracorriente del nacionalismo y de su discurso de mestizaje, entonces dominante.

Los murales están marcados por ese tipo de narrativa. Pintados en distintos momentos a partir del año 2001, cuando en el noreste de Guanajuato se impulsaba ya el reconocimiento a los derechos indígenas (Jasso, Vega, 2014), son resultado de la intervención directa de la planta docente y de algunos egresados, así como de la participación de los alumnos de la primaria y de un par de artistas externos asociados con un proyecto educativo institucional de filiación multiculturalista que, como se especificará más delante, involucró a varias instituciones del gobierno de la entidad. El primero de los murales está ubicado en la parte trasera de un aula aunque, como ya se ha señalado, la imagen se ofrece frontal a quien entra a la primaria; el segundo y más experimental se encuentra en la pared perimetral del campo de futbol, y el último tiene como soporte el respaldo de las gradas del salón de usos múltiples.

Ejecutado durante 2001, el primer mural ofrece el ensamblaje de un poema de corte etnicista con la representación plástica de elementos propios de las mayordomías y la ritualidad otomí (véase imagen 4). Tanto el poema como las imágenes señalan recursos de carácter particular, desde el distintivo término de "tashíngues", despectivo que les adjudicaron sus vecinos de la cabecera de Tierra Blanca y que los propios otomíes adoptaron reivindicándolo con un timbre de orgullo cultural, hasta el uso del copal y el sahumador como objetos rituales. Algunos de los versos incluidos, por cierto, se reproducen en el cubo de bienvenida al plantel escolar.

La idea del mural de la escuela [en el que se plasma el poema] nació porque la Comisión Nacional para el Desarrollo de los Pueblos Indígenas (CDI) pidió prestada la cancha de la escuela para un evento y le pidieron a [al profesor] Aristeo que diera la bienvenida. Vieron el extracto del poema, porque entonces íbamos a clases de ñahañu. A partir de ahí nació el ¿por qué no sacar esas ideas? Luego Aristeo las complementó, agregó después eso de que "somos flor, copal y canto" para ponerlo en el mural. ${ }^{9}$

9 Entrevista al profesor León Rodríguez, Comunidad de Cieneguilla, Tierra Blanca, Guanajuato, 27 de septiembre de 2019. Cabe añadir que este poema fue reutilizado, con un sentido semejante, en una pintura mural realizada en 2009 en el jardín público de la comunidad de Cañada de Juanica. 


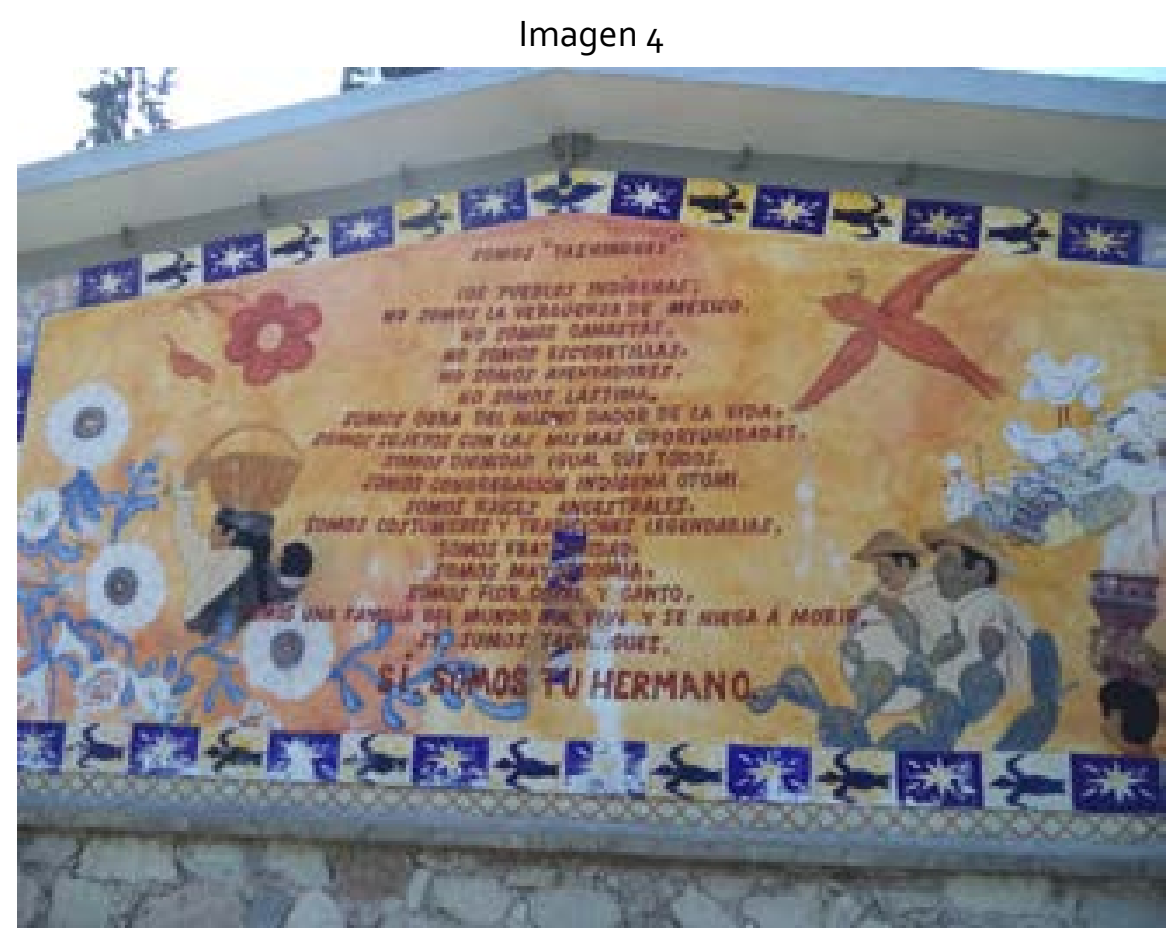

Mural con iconografía referida a las mayordomías otomíes, Escuela Primaria Miguel Hidalgo, Cieneguilla, Tierra Blanca, Guanajuato.

El poema, que es un alegato a favor de las especificidades culturales otomíes, interactúa claramente con la imagen. Esta última, ejecutada por Nahúm Rodríguez Viñez, exalumno del plantel y diseñador gráfico que cuenta con algunas otras obras de promoción a las mayordomías de la congregación (carteles publicitarios de las fiestas religiosas, por ejemplo), esboza la lógica ritual de ofrecimiento de bienes de consumo: a la derecha del mural se presentan como ofrendas los grandes panes cubiertos con papel y con pequeños pájaros de dulce que los mayordomos suelen intercambiar entre sí y para beneficio público en fechas señaladas por el calendario ritual. Este ofrecimiento sugiere y obliga a la reciprocidad en términos de ayuda y trabajo entre donantes y consumidores. La reproducción de una imagen de San Ildefonso, patrono del lugar, la presencia de una madre con su hijo, de los músicos tunditos - que sólo tocan en momentos ceremoniales específicos-, de manufacturas locales como canastas, sahumadores y la floresta elaborada ritualmente con cucharilla silvestre (recolectadas en incursiones específicas hacia cerros circundantes), aluden a formas de organización que tienen la lógica del intercambio como fundamento social.

Se trata pues de la representación de una dimensión valorativa y normativa que está presente en la vida cotidiana de las comunidades, ofrecida aquí a los alumnos como un modelo de organización social ético e integrador. Esta expresión plástica, planeada con antelación y ejecutada en pintura vinílica sobre concreto, es punto de referencia narrativa para los dos mu- 
rales posteriores, pintados ya durante la vigencia de la ley indígena estatal, que reconoce la configuración culturalmente diversa de Guanajuato, y se propone defenderla y conservarla mediante la consulta del gobierno con los "pueblos originarios", a su vez integrados en un Consejo constituido para tal efecto. ${ }^{10}$

Ya en esa línea, el segundo mural fue resultado de un proyecto sustentado en la idea de educar a través del arte, planteado por la Secretaría de Cultura de la entidad, el Instituto de Arte y Cultura, y las autoridades educativas guanajuatenses (véase imagen 5). En concordancia con los profesores escolares, el equipo Tráfico Libre de Conocimientos (TLC) impulsó un proyecto de "rescate de tradiciones y costumbres indígenas" denominado B'ede, que en hñäñhu alude a "historia o narración". ${ }^{11}$ Encabezado localmente por dos artistas profesionales, el equipo estuvo durante dos ciclos escolares (2015 y 2016) trabajando con los alumnos de la primaria, haciendo recorridos de campo junto con los niños, filmando videos, promoviendo actividades manuales y organizando presentaciones de títeres o mojigangas. Con ellos definieron las imágenes que serían plasmadas en el mural:

[los artistas] hicieron grupitos de investigación, los niños iban con los adultos a preguntar sobre leyendas, cuentos. De ahí propusieron a la serpiente como el manantial de la comunidad, cosas del náhual, el sol y la luna... retomaron imágenes que vieron en las [antiguas] capillas [como el águila bicéfala]. Cosas que tienen que ver con la identidad. ${ }^{12}$

10 Para una discusión sobre este proceso, complejo y lleno de aristas, véanse los artículos incluidos en Ventura y Uzeta (2017).

11 De acuerdo con su página, este proyecto consiste "en implementar un proceso de enseñanza-aprendizaje con estudiantes de la escuela primaria Miguel Hidalgo en la comunidad de Cieneguilla, Guanajuato, a través de prácticas artísticas actuales". Véase en línea la página http:// www.bede.org.mx/ (consultada el 13 de marzo de 2020).

12 Entrevista al profesor Celestino García Cruz, Comunidad de Cieneguilla, Tierra Blanca, Guanajuato, 11 de marzo de 2020. 


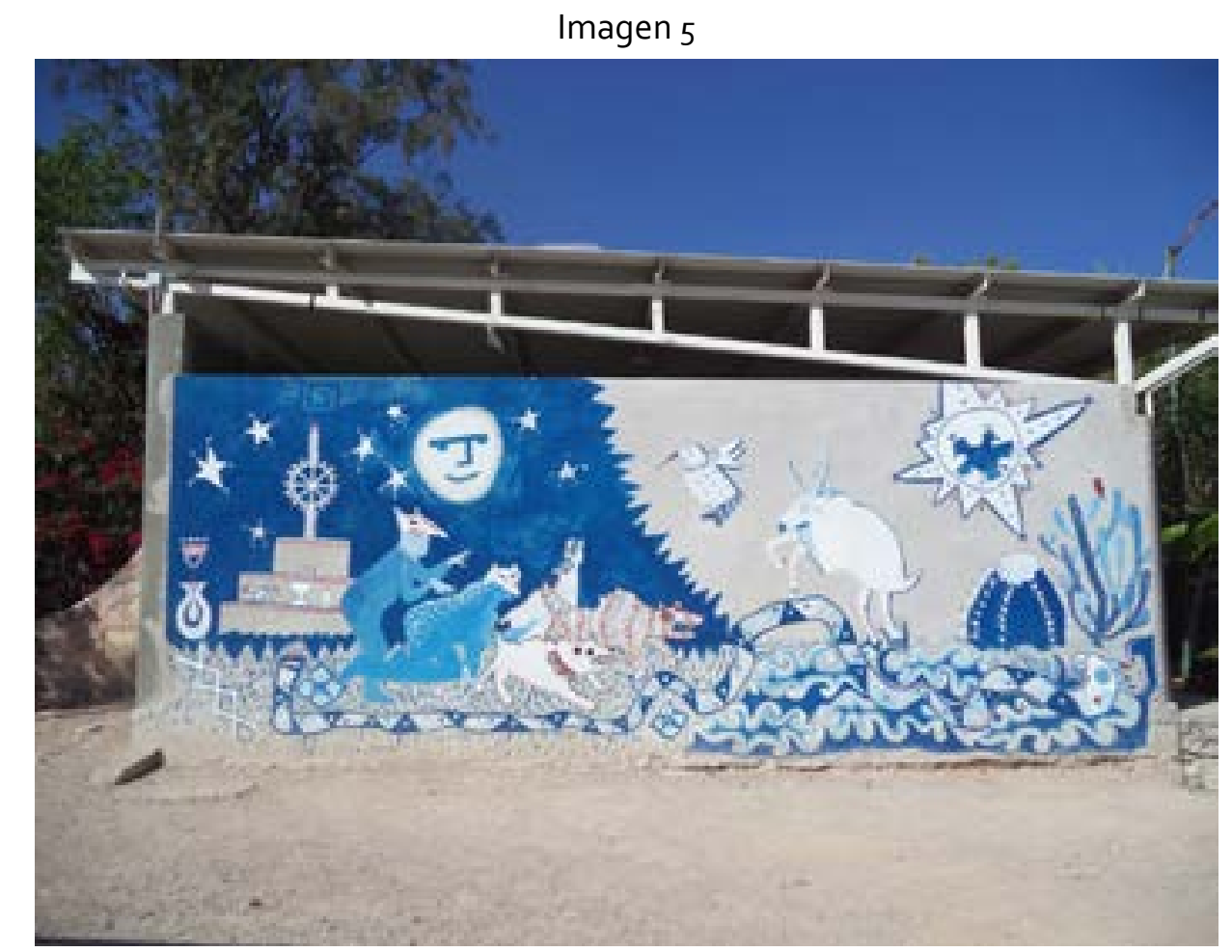

Mural con iconografía relacionada con mitología otomí, Escuela Primara Miguel Hidalgo, Tierra Blanca, Guanajuato.

El mural reproduce la "presencia permanente de la dualidad", que se repite a lo largo de todas las acciones rituales otomíes (Peña, 2019: 199). Refiriendo a identidad y a cierta dimensión cognoscitiva, es por completo una representación de la mitología local, plagada de fuerzas de la naturaleza cuyas expresiones, moralmente ambiguas, están representadas por seres con un pie en la animalidad y otro en la humanidad. Existen cuentos y testimonios locales que refieren a este tipo de ambivalencia (véanse en López, 2006), sin embargo, el mural conjuga una serie de referencias más directas al nagualismo en el contexto de un entorno árido. Aquí el sol y la luna, la noche y el día, los espacios naturales y los espacios rituales aludidos a la izquierda, mediante el basamento o "espianito" que se utiliza para descansar símbolos rituales muy valorados (como la Santa Cruz), se contrastan y comparten características de género, mientras animales a ras de piso y otros con mayor envergadura parecen dispuestos a enfrentarse.

Esos animales suman símbolos políticos y religiosos de carácter abierto, como el colibrí y la serpiente acuática, que guardan connotaciones territoriales, o los lobos y perros, que aluden a su defensa. El águila bicéfala, por su parte, puede tener referencias múltiples y finalmente muy abiertas: al dominio colonial, a cierta iconografía prehispánica que se encuentra presente en glifos y pinturas rupestres de la zona, o incluso al catolicismo otomí, que suele referenciarlo con Cristo (Peña, 2019: 201). Realizada en pintura vinil acrílica sobre un aplanado de cemento, 
este mural puede asumirse como colectivo en función de la investigación previa para definir su diseño, un contrapunto a su ejecución, confiada a manos expertas.

El tercer mural, que ha sido el último en ser realizado y que de hecho aún se encuentra en proceso, aprovechó la construcción de la cancha de usos múltiples que el profesor Aristeo solicitó en un evento público al presidente Vicente Fox (2000-2006) en una de sus visitas. Como la escultura de Hidalgo, la pintura nos regresa a la historia patria en su versión oficial, recreando varios tópicos del muralismo mexicano de la posrevolución: la conquista española con su cruel soldadera, la esclavitud indígena que clama liberación y, finalmente, la gesta independentista encabezada por un embravecido cura Hidalgo (véase imagen 6).

Imagen 6

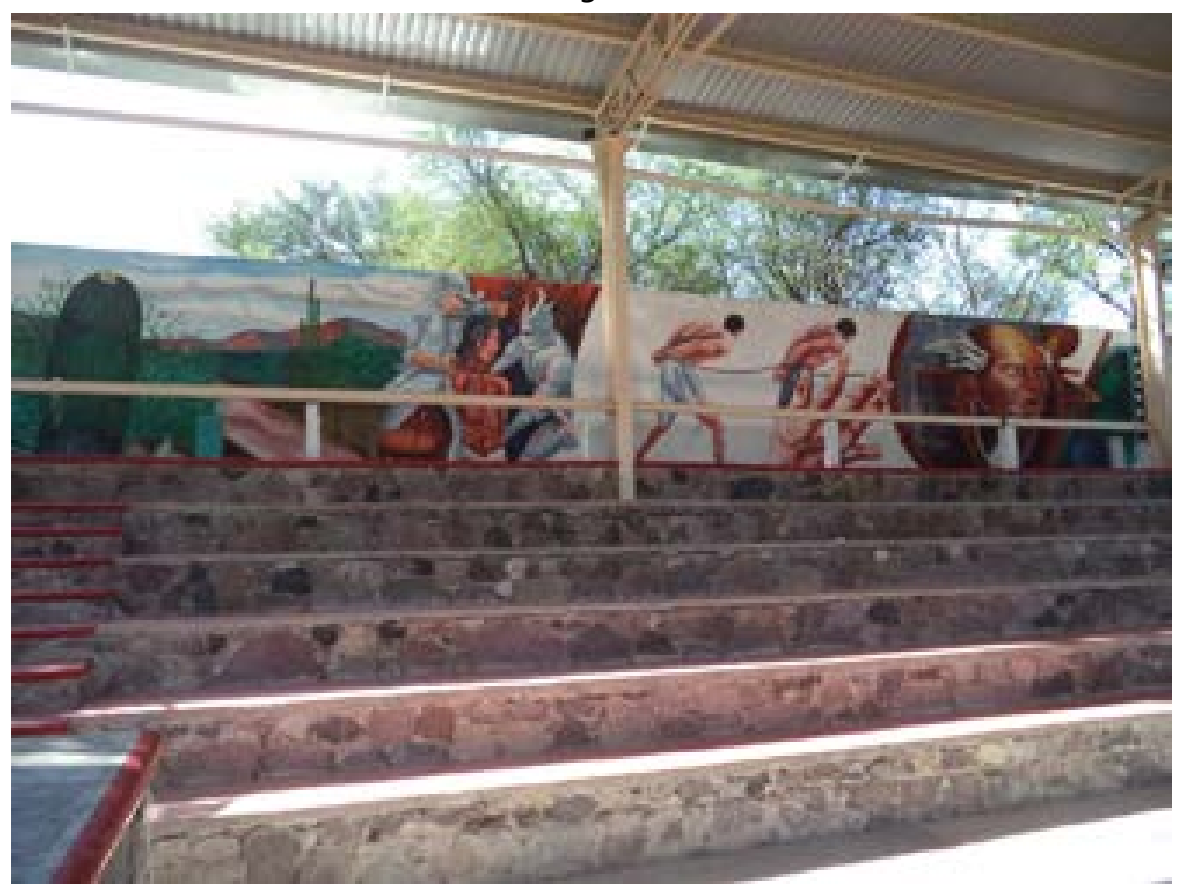

Mural con iconografía relacionada con el periodo colonial y la independencia, Escuela Primaria Miguel Hidalgo, Cieneguilla, Tierra Blanca, Guanajuato.

Su origen es quizá más azaroso que los dos anteriores, pues fue iniciativa personal de un docente que no tiene estudios de pintura — como él mismo asegura - pero que es un entusiasta del arte y lo practica. El maestro Arnoldo Chavero Licea suele recurrir al dibujo en sus clases sin que éstas sean "clases de dibujo", muy en consonancia con un comentario del director escolar: "nos dimos cuenta de la emoción del niño a través del dibujo". Esta perspectiva, además, encaja con la línea de "arte y cultura" para una escuela de tiempo completo. De acuerdo con el testimonio del profesor Chavero: 
Ya teníamos la pared aplanada y les platiqué a los [otros] maestros [del mural], pero no se había hecho nada porque cuando llovía todo caía en la barda, que estaba enlamada. Un compañero tenía amistad con gente de la presidencia municipal de Tierra Blanca, les comentó y ellos aprobaron que se hiciera una canaleta para que no afectara la barda. Cuando se hizo ya se pudo pintar [...]. Los del comité de padres de familia dijeron "cuánto [dinero] necesita para pintar", [los niños, en tanto] me hacen preguntas: quién le enseñó a pintar, se acomiden y ayudan, les presto la brocha y el pincel. ${ }^{13}$

Las imágenes plasmadas sobre aplanado de concreto fueron copiadas de un libro sobre Miguel Hidalgo impreso por el municipio de Dolores-Hidalgo, si bien el profesor Chavero les dio un orden incorporando en la obra referencias paisajísticas propias de la congregación y dejando lugar para la posterior culminación del mural con imágenes sobre "la libertad: hay una puerta inconclusa, que es la de una cárcel, y luego van caballos hacia la libertad. Quiero poner cosas de las tradiciones de aquí, un escudo nacional y los símbolos de aquí". Desde luego, al referir a tradiciones y simbología local no alude a otra cosa que no sea el amplio bagaje de la ritualidad religiosa otomí.

En esta última pintura se destacan tres elementos que están en concordancia con el poema del primer mural y con la mitología local representada en el segundo: el ya mencionado gesto de ruptura del cura Hidalgo, antecedido por una mano crispada que parece clamar por ayuda (véase imagen 7); la ubicación de la historia nacional en el entorno semidesértico propio de las comunidades otomíes, asociando la esclavitud colonial y la independencia con la población local, y muy destacadamente la ausencia de alusiones al mestizaje. Así pues, aunque la pintura pretende recrear acontecimientos históricos, su discursividad alude a una dimensión identitaria y valorativa mediante un esencialismo cultural colocado más allá de los sucesos que pretende representar. Las imágenes restantes, aún en proyecto, terminarían por reforzar esta tendencia.

13 Entrevista al profesor Arnoldo Chavero Licea, comunidad de Cieneguilla, Tierra Blanca, Guanajuato, 11 de marzo de 2020. El profesor suele hacerse de material a partir de los sobrantes generados en periodos electorales, en particular, solicitando los remanentes de las pinturas con que se publicitan los diferentes partidos en las bardas del municipio (por lo general pinturas vinílicas). Es el material que comparte con sus alumnos y que utilizan en sus cursos. 


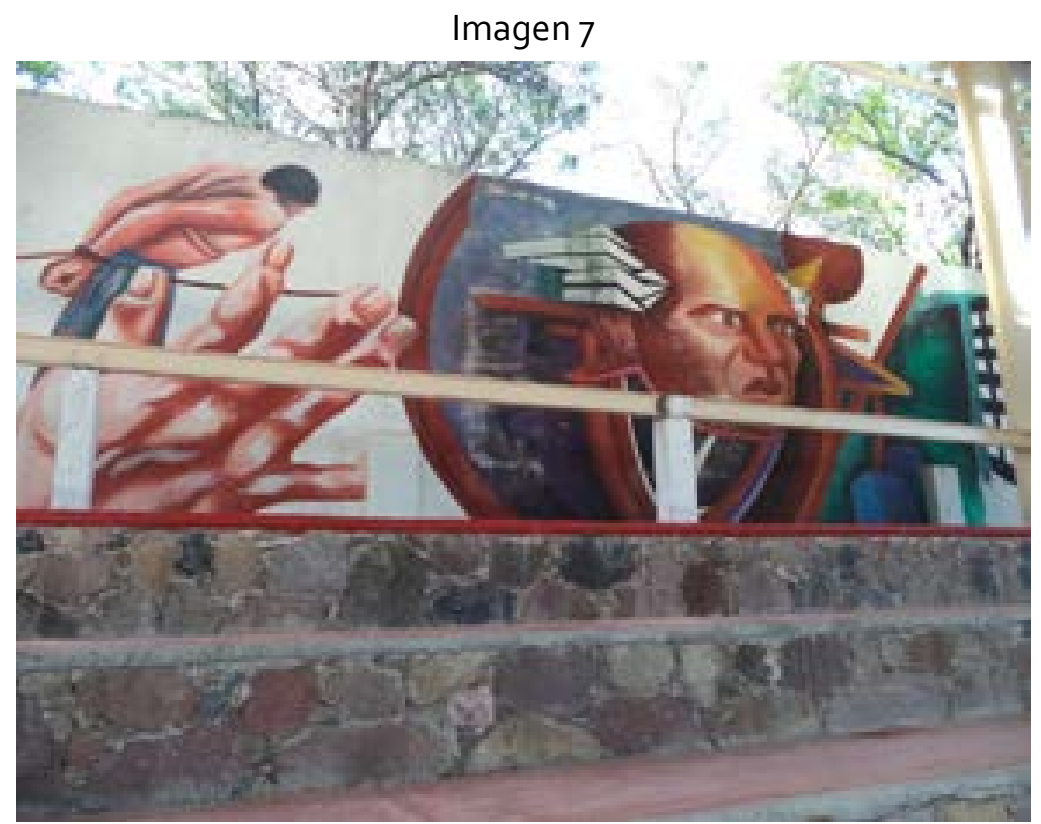

Detalle del rostro de Hidalgo en el mural que representa la conquista y la independencia, Escuela Primaria Miguel Hidalgo, Cieneguilla, Tierra Blanca, Guanajuato.

Los tres murales, en suma, expresan la narrativa política de las comunidades y la manera en que los maestros, inicialmente alrededor del profesor Aristeo, estuvieron involucrados en el proceso que llevó a la redacción y aprobación de la ley indígena en la entidad. Ejecutados sobre la marcha, sin atenerse a un plan preestablecido pero aprovechando oportunidades al paso, los dos últimos murales son resultado de los efectos iniciales de aquella ley, reforzando visualmente lo que sería su punto de partida local: la singularidad cultural de la congregación debe ser el sustrato sobre el que las comunidades y las instituciones estatales interactúen. Siguiendo esa lógica, los murales pretenden fortalecer la condición presuntamente esencial de aquella particularidad otomí entre los alumnos, llevando al campo de lo escolar —al propio edificioprácticas, creencias y conocimientos enraizados en la vida cotidiana.

\section{Conclusiones}

Con su bandera nacional y su bienvenida bilingüe, la Escuela Miguel Hidalgo es en muchos sentidos la expresión física del proceso de cambio local verificado en la congregación durante las últimas siete décadas. Vista desde los intereses de las comunidades otomíes, a través de su concreción arquitectónica ha llegado a representar de manera permanente la que en su momento fue la mayor victoria política en contra de sus vecinos mestizos, lo mismo que una posibilidad de futuro para sus niños. No es un dato menor que ese triunfo fuera compartido entonces y a partes iguales con la parroquia católica y el gobierno de la entidad.

Como arquitectura y como soporte simbólico, el plantel se ha convertido en un lugar para dialogar con los representantes y con las diferentes instituciones del Estado mexicano y del 
gobierno de la entidad, lidiando con las variaciones del proyecto de educación pública para responderlas, ajustarlas y reajustarlas hasta su completo arraigo (Vaughan [1997], 2001:19; Calderón, Martínez, 2012). No obstante, la escuela ha enraizado a partir de los términos propios de la vida cultural de la congregación, y una primera alusión al respecto es que, en su conjunto, la iconografía del plantel contextualiza localmente segmentos de la historia nacional hermanándola en una misma narrativa con personajes del lugar, y con mitologías y formas vivas de organización social.

En efecto, pese a sus referentes formalmente heterogéneos (un héroe nacional, varias ofrendas para el intercambio ritual, dos o tres naguales, etc.), los murales plasmados sobre un soporte físico institucional y diseñados sin haber sido ajustados a una planificación detenida y previa, constituyen parte de una narrativa con visos de coherencia. Si bien sus imágenes se encuentran a medio camino entre la endoculturación y lo que propiamente es la educación pública, la narrativa que las articula alude a la permanencia y adecuación de pretendidas esencias culturales, útiles para la reproducción de las comunidades congregadas como localidades específicamente otomíes, es decir, como agrupamientos basados en una serie de valores y prácticas vigentes, supuestamente inamovibles y autoatribuidas: el intercambio, la ritualidad, la dualidad como principio ordenador, la identidad específica.

Como soporte simbólico, el plantel escolar ha sido diseñado en diferentes momentos y de manera azarosa como un espacio para reafirmar la pretendida esencialidad de ciertas prácticas y características locales, reiterando dentro del ámbito escolar las dimensiones de la currícula cultural. La narrativa que dota de coherencia a la plástica escolar procede de ahí mismo, lo que revela su sentido político. $\mathrm{O}$ dicho con mayor propiedad, la narrativa de la que derivan los murales y toda la iconografía del plantel, es política justamente porque es cultural.

Es pertinente señalar —o reiterar- algunos asuntos sobre el papel pedagógico de la plástica escolar en la recreación de la identidad diferencial. La iconografía utilizada en la escuela es presa de una paradoja, pues como grupo de imágenes producidas en momentos específicos, o bien como expresiones contextualizadas, pretenden ser la representación de elementos esenciales que escapan al correr del tiempo. En esos términos resulta claro que las imágenes no están en esos muros ni en esas tallas por el gusto estético de la planta docente, o para formar a los alumnos en él, aunque esto último pudiera suceder. No se trata, en suma, de arte; las imágenes han encontrado accidentadamente su lugar ahí por una intención política preexistente, ésta sí sustentada en un imperativo pedagógico: con ellas se pretende expresar los fundamentos socioculturales de la identidad otomí. Los murales y su iconografía complementaria forman las representaciones con las que los alumnos tendrán que contrastar su propio desarrollo, no en lo individual sino en lo colectivo. Las imágenes pretenden, pues, modelar experiencias históricas, futuras y grupales, desde la recreación de una identidad diferencial presuntamente fija. 


\section{Referencias}

Aguirre, G. (1988). Formación de una teoría y una práctica indigenista. En Instituto Nacional Indigenista 40 años. México: Instituto Nacional Indigenista, 11-40.

Bourdieu, P. (1991). El sentido práctico. España: Taurus.

Buxó, J. (2002). El resplandor de las imágenes. México: Universidad Nacional Autónoma de México.

Calderón, M.; E. Martínez (eds.) (2012). Educación indígena, ciudadanía y estado en México del siglo XX. México: Benemérita Universidad Autónoma de Puebla, El Colegio de Michoacán.

Civera, A. (2012). Honores y ultrajes a la bandera: la escuela, la democracia y la intolerancia en el México de los años cuarenta. En Calderón, M.; E. Martínez (eds.). Educación indígena, ciudadanía y estado en México del siglo XX. México: Benemérita Universidad Autónoma de Puebla, El Colegio de Michoacán, 69-92.

CONAEN (2020). Los Normurales. Un grito de resistencia y color por la memoria. México: Ediciones Normalismo Extraordinario.

Crespo, J. (2010). Contra la historia oficial. México: Random House Mondadori.

Ginzburg, C. (2014). Miedo, reverencia, terror. Cinco ensayos de iconografía política. México: Editorial Contrahistorias.

Hewitt, C. (1988). Imágenes del campo. La interpretación antopológica del México rural. México: El Colegio de México.

Jasso, l.; J. Vega (2014). Reconocimiento de los pueblos indígenas en Guanajuato. Procesos de negociación de una ley indígena. En Guzmán, R.; E. Guzmán (coords.). Organización y conocimientos. Manejo de recursos en regiones rurales de México. México: Universidad Autónoma de Morelos, 121-142.

López, F. (coord.) (2006). Mi abuelo me contó. México: Registro en trámite, edición del autor.

México Indígena (1978). INI 30 años después. Revisión crítica. México: Instituto Nacional Indigenista.

Pastrana, L. (2014). Abordaje antropológico de procesos educativos no escolarizados: curriculum cultural y aprendizajes comunitarios en Santa Clara Coatitla, Ecatepec de Morelos en el Estado de México. En Martínez, E. (coord.). Repensar la educación desde la antropología: sujetos, contextos y procesos. México: Publicaciones de la Casa Chata, 105-141.

Rivera, B.; S. van Dijk (2017). Prácticas interculturales de una primaria bilingüe otomí en Guanajuato, México, ponencia, Congreso ALAS XXXI. Uruguay.

Sigüenza, S.; G. Fabian (2013). Historia de la educación indígena en la configuración del Estado nacional y la ciudadanía en México. En Bertely, M.; G. Dietz; M. Díaz (coords). Multiculturalismo y Educación 2002-2011. México: ANUIES/COMIE, 81-115.

Urbina, M. (2016). Urdir comunidad en tierra yerma. Reconstitución/desestructuración en la congregación otomí de San Ildefonso de Cieneguilla, Tierra Blanca, Guanajuato, Tesis Doctoral en Ciencias Sociales. México: El Colegio de San Luis. 
Uzeta, J. (2004). El camino de los santos. Historia y lógica cultural otomí en la Sierra Gorda guanajuatense. México: El Colegio de Michoacán y Ediciones La Rana.

Uzeta, J. (2010). La relevancia política de documentos tardíos. Propiedades privadas en una congregación indígena. En Roth, A. (ed.). Caras y máscaras del México étnico. La participación indígena en las formaciones del Estado mexicano. México: El Colegio de Michoacán, 95-110.

Vaughan, M. ([1997] 2001). La política cultural en la Revolución. Maestros campesinos y escuelas en México, 1930-1940. México: Fondo de Cultura Económica.

Ventura, M.; J. Uzeta (2017). Derechos indígenas en disputa. Legislaciones estatales y tensiones locales en México. México: El Colegio de Michoacán / El Colegio de San Luis.

Zárate, J. (2015). La identidad como construcción social desde la propuesta de Charles Taylor. Eidos Revista de Filosofía, (23), 117-134. 